\title{
The Locational Dynamics of the Japanese Plastic-Mold Manufacturing Industry during the Microelectronics Innovation
}

\author{
Hironobu Oda \\ Junior College of Toyota, Toyota, Aichi, 471, Japan
}

\begin{abstract}
The purpose of this paper is to investigate the locational dynamics of the Japanese plastic-mold manufacturing industry during the microelectronics innovation, as a typical example of the small- and medium-sized machinery industries. The plastic-mold manufacturing industry started around 1930 and a complex developed in Southern Tokyo. The development of mold technology formed the basis of the mass production of durable customer goods with dependence on skilled labor. When the Japanese industry as a whole experienced drastic decentralization in the 1960s and early 1970s, the mold industry maintained centralization in existing industrial regions. However, the recent technological innovation caused rapid locational dispersal into peripheral areas of the industry and the regional differentiation of production. The above facts do not conform to the hypothesis in the neo-Marshallian flexible specialization approach, which proposes that the diffusion of ME devices and flexible production methods resulted in "re-regionalization". The innovation had the effect of producing spatially wider networks of small- and medium-sized manufacturers around the existing agglomeration structure.
\end{abstract}

Key words: technological innovation, product cycle, division of labor, external economies, the machinery industry, small- and medium-sized enterprise

\section{Introduction}

The microelectronics (ME) innovation has progressed since the 1970 s and the realization of diversified small-quantity production attendant on it have effected industrial location in advanced industrial countries and Asian countries (Piore and Sabel 1984; Scott 1988a; Sabel 1989). What has been proposed in the recent flexible specialization approach is that the ME innovation caused "re-regionalization" of the small and medium enterprises. However, at least as to the Japanese industries, there is no reason to support the idea.

Surely, many researchers have suggested that the Japanese production system exhibited spatial concentration or clustering of smalland medium-sized enterprises. In particular, the Japanese machinery industries have drawn a great advantage from large agglomerations of small-sized machinery shops in intrametropolitan industrial regions (Takeuchi
1973, 1978, 1983; Seki and Kato 1990). The recent innovation, however, had an effect on the geography of the Japanese machinery industries.

Circumstances of the industries and the industrial regions have been analyzed by different academic specialists and administrative bodies. Locational dispersal of industries with the innovation in the 1980s has been "the second boom of industrial dispersal" following the one in the 1960s and the early 1970s (Hori 1985). This boom is characterized not only by spatial expansion of the location of industries to outer areas, but also by industrial decentralization to distant areas (Ukai 1994). Akaike (1990) insists that changes in land use of the intra-metropolitan industrial regions should be understood by changing corporate behaviors with the innovation. Watanabe (1990), who analyzed intra-metropolitan industrial regions from the standpoint of subcontracting system study, pointed out that segregation or regional specialization arises according to whether or 
not small businesses can move out from the regions.

The question we have to ask here is how the innovation affected the locational configuration of Japanese small- and medium-sized machinery industries. The purpose of this paper is to elucidate the logic of locational changes of the plastic-mold manufacturing industry as one example of small- and medium-sized machinery industries during the $\mathrm{ME}$ innovation in the context of locational change studies.

Mold (or die) means metal patterns to form a large number of identical goods using plastic or fluid materials. There are several kinds of molds (or dies) such as molds for metal press, for plastic injection, for forging and for casting according to the kind of materials used. The mold is generally included in the category of general-purpose machinery parts, just like screws and springs, because they can be recognized as parts of any machines such as metal press machines or plastic injection machines. One fifth of the molds that are used by assembly makers and plastic-molding companies are in-house productions, while four fifths are made by plastic-mold manufacturers. ${ }^{1}$ Such a high ratio of outside orders by users shows the sophisticated technology that mold production requires. Mold technology is a basic technology of machinery industries (Seki 1994), while the mold manufacturing industry is a basic industry of machinery industries (Takeuchi 1972).

This industry has kept the tendency to concentrate on existing industrial regions using skilled labor and mold-related processors (subcontractors). However, the industry rapidly moved to peripheral areas with the innovation as the basis for diversified small-scale production of durable consumer goods in the $1980 \mathrm{~s}^{2}$ This study analyzes and considers mainly the plastic-mold manufacturing industry which experienced the most drastic change of all the industries.

\section{Existing Studies and Methods}

\section{Technological progress and changing locatio- nal tendency}

Geographical surveys about technological progress and locational change are not new. Hoover (1937) explained locational shifts in the US leather industry according to diffusion of strong tannin acid or inorganic tannin acid. Isard (1948) pointed out the transformation of locational tendency of the steel industry according to the development of furnaces. They were conscious of the distance between the material site and the factory in conformity with Weber's theory of industrial location. However, when we consider the locational dynamics of small- and medium-sized industries, an involvement with the external economies of the intrametropolitan industrial regions is more important than the relationship with the material site. Therefore, it is more useful to refer to the progress in the product cycle theory and the incubator hypothesis than to neoclassical locational theories.

The product cycle theory was first applied to the analysis of multinational corporations by researchers at Harvard University. In this theory, a life cycle of a product or an industry is divided into three stages: the initial (or innovation) stage, the growth stage and the standardization (or maturing) stage. The production depends on the external economies of the mother country (central area) until the technology is standardized. When the technology achieves standardization, the production process moves to a developing country (peripheral area) to reduce labor costs.

The product cycle thus suggests a general framework to interpret the decentralization of production at several spatial scales (Norton and Rees 1979). The theory was applied to many studies in economic geography and regional planning in the 1970s. For example, Thwaites (1978) who examined the roles of the mobile plant in the self-sustained economic growth of the Development Area in Britain, referred the transfer of production to branch plants for acquisition of scale benefits, in line with taking the product cycle theory. Oakey et al. (1980), who focused on intra-company transfer of innovations in the UK, pointed out that innovations produced in southeast England crystallized into products in other regions. Norton and Rees (1979), who examined industrial decentralization from the US Manufacturing Belt to the 
Sunbelt, pointed out that it is important to focus the analysis not only at the national, but also at the regional level.

When we consider the product cycle theory at the regional scale, it is necessary to incorporate it with incubator hypothesis (also called seedbed hypothesis). This hypothesis holds that the external economies within a metropolitan area work as an incubator or a seedbed for new factories. ${ }^{3}$ The intra-metropolitan external factors are the presence of cheap rental factories, secondhand machinery, diversified skills and related industries. This is concretely characterized firstly by relatively high birthrates of new establishments, and secondly by a new out-migration of successful, sufficiently matured establishments seeking space for expansion (Leone and Struyk 1976).

Thompson, an urban economist, called it the filtering-down theory of industrial location. According to Thompson, "if the larger urban areas are, in fact, more than proportionately places of creative entrepreneurship, then we might hazard a broad hypothesis on the nature of regional growth pattern" (Thompson 1968: 55). Industries filter down through the system of cities, from places of greater industrial sophistication to lesser industrial sophistication, because skill requirements decline steadily as the production process is rationalized and routinized with experience (Thompson 1969: 8). Thompson's subspecies of product cycle theory comparably emphasizes decentralization through urban hierarchy. If the term "filteringdown" in economics corresponds to the term "diffusion" in geography (Evans 1985), filteringdown has the sarne meaning as "hierarchical diffusion", which Berry (1972) uses (Rees 1979: 49).

\section{Production system, linkage system and loca- tion}

According to Scott who became a major critic of intra-metropolitan industrial geography, the above mentioned studies can be summarized in terms of a composite theory, which he designates "incubation, product cycle and hierarchical filtering theory" (Scott 1988b). He proceeds on the basis of a threefold account of (1) the presumed locational needs of small new firm, (2) the evolution of industrial technologies and products through time, and (3) the diffusion of units of productive capital down the urban hierarchy (Scott 1988b:206). On the one hand, he evaluates in some degree the composite theory containing some important considerations. On the other hand, he criticizes the theory as beginning with a disastrous biological metaphor, and discusses the incentives in the complex inner mechanisms of production systems in capitalism (Scott 1988b: 208).

In contrast, Scott's theory pays attention to production system dynamics. When vertical disintegration of the production process, namely roundaboutness of production, develops, industrial centralization advances with the complex linkage systems, because the proximity of factories is required. On the other hand, when vertical integration develops, dispersed location becomes prevalent, because of the decreasing importance of transport cost. In other words, when the input-output relation is simplified or standardized, industrial decentralization arises. The product cycle theory emphasizes routinization of labor as a course of decentralization, while Scott emphasizes the simplification of the linkage system.

There are some empirical surveys in light of the internal logic of production. Lichtenberg (1960) shows the case of the US radio industry. Largely a small-scale labor intensive sector in the 1920 s and 1930s, the industry was transformed into a capital intensive sector with the move from the New York region to the Midwest.

As an example of the textile industry, Steed $(1970,1971)$ explains the decentralization of the linen industry in Northern Ireland. The factories that had been small, diversified, and concentrated in Belfast, moved to peripheral areas with reorganization within a few major integrated producers in the 1950s and 1960s.

Among many studies on the dress industry, Martin (1966) points out the dispersing tendency from London in the plants that massproduce cheap dresses. Cameron and Evans (1973), who also mentions the decentralization of the UK dress industry, find that the standardization of input-output relations results in locational dispersal. 


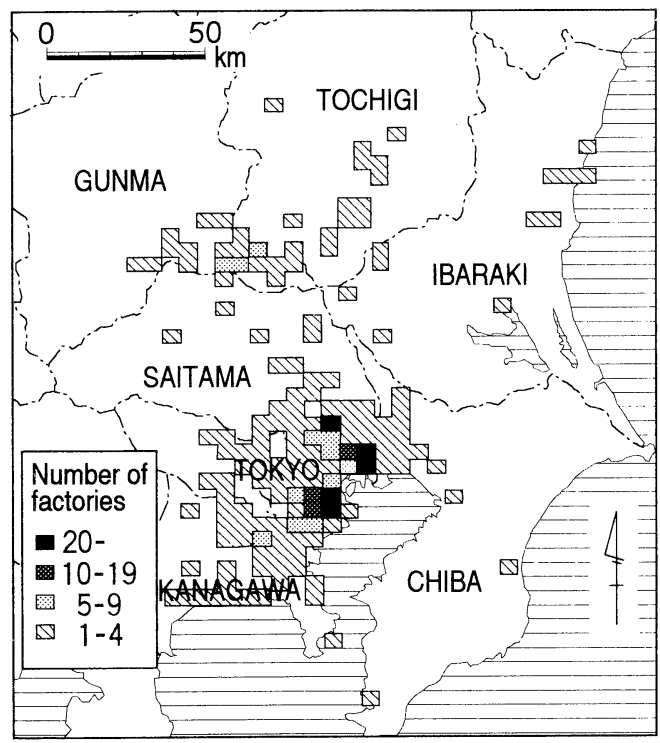

Figure 1. Distribution of the mold and die factories with 10 or more empoyees in the Tokyo region and the peripheral area, 1972.

Source: Based on The General List of All Factories in Japan.

In those cases, two points can be indicated. First, those studies took mainly the textile industry and the durable consumer goods industry before the 1960s as their subjects. Second, no one referred to the active innovation. In contrast, the progress in decentralization of small- and medium-sized machinery industries has been brought after the late 1970s, taking the ME revolution opportunity. Although there are many studies on the diffusion pattern of NC (numerical controlled) machine tools (Thwaites 1982; Rees et al. 1984; Gibbs and Edwards 1985; Kleine 1985; Harris 1988; Alderman and Davies 1990; O'Farrell and Oakey 1992), little is known about locational dynamics of machinery industries attendant on it.

We need to re-examine the "re-reginalization" hypothesis from the standpoint of locational dispersal studies based on production system dynamics.

\section{Methods}

This paper consists of two parts. The first half considers technological progress in the Japanese plastic-mold industry and its implications, to clarify how the innovation has pro-

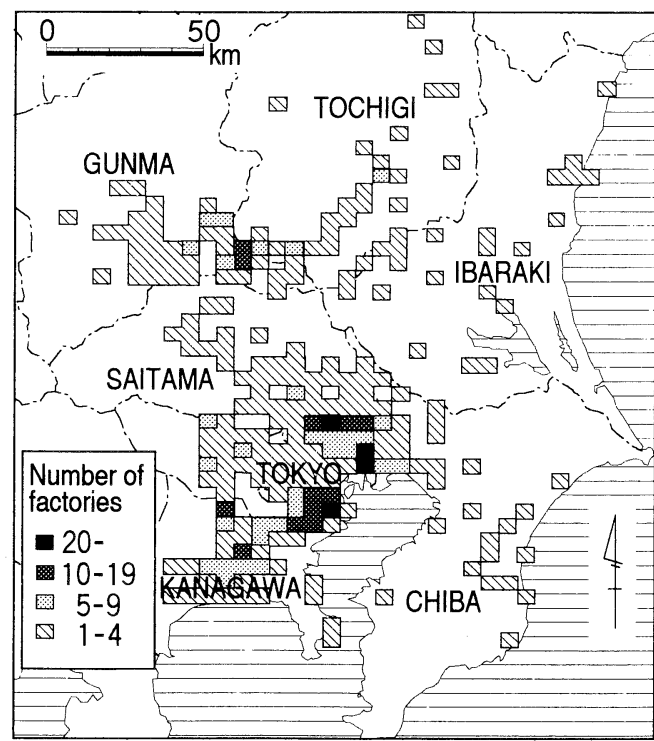

Figure 2. Distribution of the mold and die factories with 10 or more empoyees in the Tokyo region and the peripheral area, 1988.

Source: Based on The General List of All Factories in Japan.

gressed and how it has effected locational tendency in the industry. According to the above review, we need two viewpoints which elucidate the locational dynamics of the industry during the innovation: (1) how skilled labor is substituted by capital equipment and (2) how the production system is simplified.

The second half looks at the level of individual factories in a peripheral area (Southwestern Ibaraki bordering the northeast fringe of the Tokyo Metropolitan area) as compared with the mold production system in an intrametropolitan industrial region (Southern Tokyo, so-called "Keihin area" in which the mold industry has developed since before the Second World War). The author reports mold production in Southern Tokyo in a companion paper (Oda 1997). We can assume two types of "peripheral area" as follows. First is "peripheral" on a nationscale. Second is "peripheral" on a regional-scale (or metropolitan-scale). It is likely that both types of peripheral location have many characteristics in common. That is to say, neither of them has the advantage of external economies. We choose the latter type as a microcosm. Figures 1 and 2 show outward expansion to the 
surrounding neighborhood of the existing agglomeration areas on the one hand, and decentralization to peripheral areas such as Ibaraki and Chiba Prefectures on the other hand.

Before the field survey, the author prepared a database of the mold industry using The List of Mold Factories edited by Machinery Economic Press, The General List of All Factories edited by the MITI, the yellow pages edited by NTT and the various lists of factories edited by local public corporations. The interview of factories which were randomly selected out of the database were carried out between August 1993 and June 1994. The analyses of this study are based on the database, the outcome of interview, Census of Manufactures and other material.

\section{Technological Progress and Changing Locational Tendency in the Plastic- Mold Manufacturing Industry}

\section{Periodization of technological progress}

Hoover (1937), who explained locational shift of US shoe industry, divided the evolution of the industry into four phases. As mentioned already, the product cycle theory also assumed three or four stages of product life cycle. Likewise, it is important to divide the industrial technologies into some stages when we mention locational dynamics with the technological innovations. It is necessary to elucidate through periodization how a skill has been substituted by capital arrangement, and how the mutual dependence between the manufacturers has developed or been reduced. Comprehension of the transformation of the labor force required, the capital arrangement introduction and the division of labor, is necessary to an understanding of the locational dynamics of the machinery industry.

The main process in mold manufacturing is machining. Machining signifies a series of processes that use machine tools such as drill presses, lathes, and milling machines. Machining is used for making of a single or a few products in contrast with press working and casting for mass production. The greater part of small machinery shops that constitute intra- metropolitan industrial regions have mainly carried out machining. ${ }^{4}$

The technological progress of machining can be divided into three stages in the light of the evolution of machine tools. The first is the age of belt drive type machine tools. Power was communicated to some machine tools by belts and rotation axes from a single large size motor installed in a corner of the shop in those days. The second stage was brought by the spread of direct type machine tools. Direct type machine tools are each equipped with a motor. Belt drive type machine tools need a complex power transfer device in the workshop, but direct type machine tools can be introduced without such a complex device. The spread of the direct type machine tool helped the birth of new machining processors and mold manufacturers. The third period was brought by the introduction of $\mathrm{ME}$ equipment such as NC machine tool. NC means numerical control. The machining that had depended on skills in the past was automated by computer control. The diffusion of NC machine tools supplemented a shortage of skilled labor in intra-metropolitan industrial regions and permitted machining utilizing a younger labor force in the unskilled peripheral areas.

We can also assume the same periodization for the mold manufacturing industry. The first phase is before 1960 when mold manufacturers depended on hand tools such as chisels and files. The second phase is the 1960s through the early 1970s when they depended on machine tools such as milling machines. The third phase is from the late 1970 s to the present when $\mathrm{ME}$ equipment such as NC machine tools spread.

\section{Incubation of plastic-mold manufacturing in- dustry (stage 1)}

The plastic-mold manufacturing industry was established in Japan around 1930 after the Manchurian Incident. It was the time when mass production industries were formed in the advanced industrial countries. A large demand of electric wiring apparatus and telephone exchangers after the earthquake disaster of 1923 stimulated rapid evolution of Bakelite production. Furthermore the Mark 3 telephone that developed in 1932 and is the forerunner of the 
mass produced electric appliances in Japan used many Bakelite parts.

The industry had its beginning in Southern Tokyo. Plastic-mold was produced in the very early phase for use in molding of electric insulation, telephone parts, wiring apparatus, sockets of light bulb, tableware and buttons. During the Korean War mold production for Bakelite tableware for the US Army especially developed.

Mold manufacturers did not have any milling machines in those days. Therefore, they worked with a planing machine, chisels, files and their great hand skills. This industry required high artisan skill. It took at least five years of hard training to acquire the minimum skills of an artisan, while the training period of general machinist was three years. A further five years were needed becoming independent. Because of the difficulties, Such artisans held in the high position in machinery industries of Southern Tokyo. The mold manufacturing industry was so oligopolistic that the wage of an average craftsman was more than three times of that of an average machinist.

The division of labor did not progress conspicuously in this phase. In fact they depended only on sculptors and gilders for outside process.

\section{Diffusion of machine tool and growth of the social division of labor system (stage 2)}

Important technological changes took place in the industry in the 1960s. The first was the diffusion of machine tools such as vertical milling machines for molds. The second was the spread of injection molding ${ }^{5}$ in place of compression molding. The former led the mold manufacturing industry to capital intensification and the latter promoted the development of division of labor.

First of all, the diffusion of machine tools progressed with the shift from a belt type toward direct type as mentioned earlier and with the 1956 Act to Promote the Machinery Industry. The act designated the mold as a specific machine and allowed the industry to receive specific financing from the Japan Development Bank. However, no one received financing except some large-sized manufacturers
(Tokyo Metropolitan Government 1964). Nonetheless, machine tools spread to small manufacturers after Makino Milling Machine Mfg. Co., Ltd. , a major maker of machine tools, adopted the installment in the 1960s. Mujinko system (mutual financing association) based on the regional manufacturers' cooperative, functioned effectively through the first installment sales. Ties between manufacturers in the intrametropolitan industrial regions acted profitably on introduction of machine tools.

Secondly, injection molding machines were first imported to Japan in 1951. The mold industry hastened the development of mold for injection with plastic-molding makers. They benefited from the mutual proximity between workshops at this joint development in the area.

However, the spread of injection method did not take off until the early 1960s, because domestic production of thermoplastic resin used for injection molding was lagging. Various kinds of processing technologies were introduced to make a dies for injection molding and specialized labor division in the industry developed rapidly in the 1960s.

Forming of more complex shapes became possible by injection molding. Complex engraving is required to make products of complex shape, therefore various kinds of producing methods were introduced. Every method needed models that had been sharpened with steel and lumber to carry out the processing. In other words, patterns for making molds were used. First, there was a method called hobbing processing. This method made the shape of a mold by beating a hard metal model (hob) against a mold plate with a hobbing press machine. Second, there was bery-processing. This processing cast an alloy of beryllium and copper to a mold core. The third was copying processing, that used copying milling machines. A tracer mounted on the machine traced a wooden pattern and a mold plate was cut according to the shape. Mold manufacturers needed to depend on specific companies for each process. They were to order subcontracting to the companies that had hobbing press machines, a specific casting arrangement, and wooden-made pattern.

A mold for injection uses some bars or pipes 


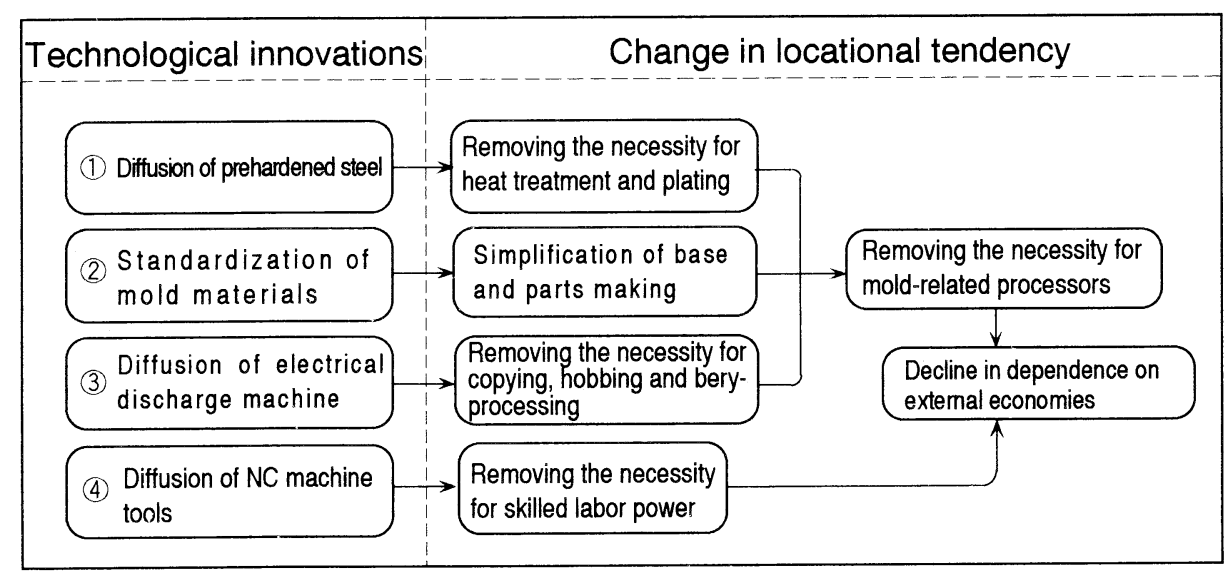

Figure 3. Changes in the locational orientation of the Japanese plastic-mold industry in the late 1970s and the 1980 s.

that guide a male mold (core) to a female type (cavity), cool the plastic and eject the product from the mold in the structure. These parts are made generally with a lathe. Mold manufacturers are experts of milling machine processing rather than lathe processing. They depended on lathe processors to a considerable degree.

A further addition to the companies outside the mold industry was heat treatment processors and etching processors. Heating treatment, which gives durability, became necessary for the mass production of plastic products based on the development of the injection method to molds. ${ }^{6}$ Etching represents leather figure, moire or granular sculpture to the surface of cavity. When plastic parts were to be employed for durable goods such as radios, television sets and motors, the necessity of etching arose to enhance the added value.

Capital intensification is thought to be an important factor of the geographical decentralization of the workshop, but skills born in the industrial district ware still required to operate machine tools. And the evolution of the division of labor between manufacturers had the function of restricting location to the agglomeration region. Accordingly, there was no real movement to decentralization at this stage.

\section{Development of ME technology and standard- ization (stage 3)}

Various kinds of process innovation have been brought about since 1970 in the plastic- mold manufacturing industry (Figure 3 ) by wedded advancement in mechanical and electronics technology.

First of all, the diffusion of prehardened steel was proposed. Prehardened steel has hardness necessary for the mold beforehand. As mentioned above, mold manufacturing needed heat treatment and plating to enhance its hardness after sculpture process. But mold manufacturers need not always depend on heat treatment manufacturers and platers to give durability to the mold with the spread of prehardened steel. The "NAK55" prehardened steel that Daido Steel Co., Ltd. and Japan Mold Materials Co., Ltd. developed jointly in the first half of the 1970s led the spread.

The second was the standardization of mold base $^{7}$ and parts. Standardization had been tackled from the early period when some staff members of the Japanese Productivity Center visited the United States to inspect standardization in 1958. Japanese Industrial Standards of mold material were established afterwards, but production of standardized goods based on these standards did not develop until the 1970s.

The history of the following two large makers producing materials and parts for plasticmold shows the approximate time of standardization. Japan Mold Materials Co. Ltd., which began to supply standardized mold bases in 1976, founded a plant for the production at Kuroiso in northern Tochigi Prefecture in 1981. Futaba Co. Ltd. located in Mobara in central 


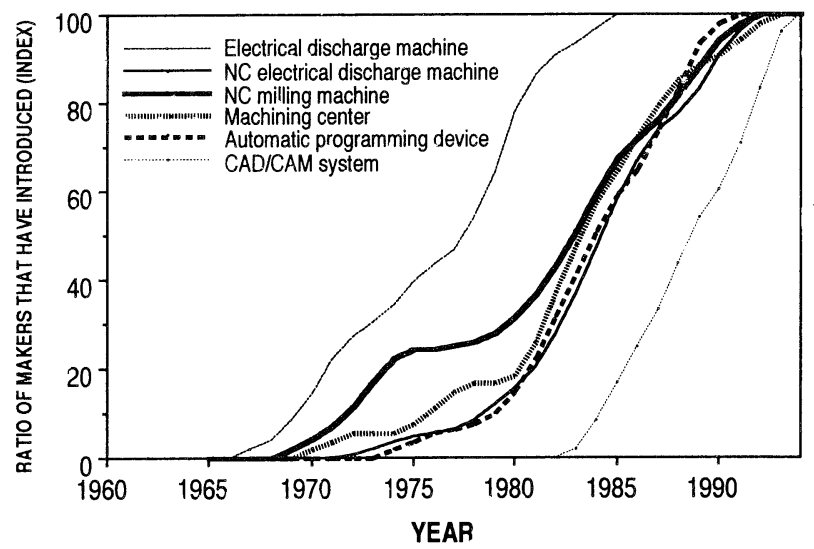

Figure 4. Introduction of microelectronics apparatus to the plastic-mold industry, 1960-1993. Ratio in $1993=100 . \mathrm{N}=51$.

Source: Based on field survey in Southern Tokyo and Southwestern Ibaraki.

Chiba Prefecture began the sale of standardized parts in 1969 and the sale of standardized mold bases in 1970. Limited at first, the number of products were enlarged between 1974 and 1979 , and a plant dedicated to mold base was established in the suburb of Mobara in 1980. Furthermore, the corporation started the sale of standardized mold materials using prehardened steel in 1983 and a new plant oriented to the market of western Japan was founded in Akashi, southern Hyogo Prefecture in 1985. Judging from above facts, standardization has progressed from the latter half of the 1970s to the first half of 1980s. Machining of standard materials internalized the grinding and lathing for which mold manufacturers had depended on specific outside companies.

The third innovation from the 1970 s was the spread of EDM (electrical discharge machining). Electrical discharge machine sculpts steel by discharging electricity from an electrode put into liquid while it was put on steel. Hobbing, bery-processing and copying which had been adapted in the second stage lost their roles with the spread of EDM.

We can place the above-mentioned three innovations as the factors that saved the necessity of some allied processors of the mold manufacturing industry. In other words, mold manufacturers no longer needed immediate accessibility to other companies within the intra-metropolitan industrial regions.

The fourth innovation is the spread of $\mathrm{NC}$ machine tools. Machine tools, such as milling machines, work by numerical control from computers. Furthermore CAD/CAM (computeraided-design and computer-aided-manufacturing) system has been diffused recently. The spread of this capital equipment brought about a variation in the required labor force. The mold industry has come to employ brain workers rather than skilled workers, namely, a young labor forces who can operate the computer easily and are suited to the realization of the scale economy. Accordingly a big change was caused to the mold manufacturing industry which had once depended on skilled machinists within the intra-metropolitan industrial regions.

The four innovations as a whole reduced the dependence on external economies of the existing industrial regions.

\section{Verification of technological and locational change}

The above-mentioned cases can be confirmed through time series data as follows. The mold industry was taken up as a category of Census of Manufactures by MITI in 1967. Though detailed analyses based on the data are an impossibility, the innovation and locational shift caused in stage 3 can be found.

First, Figure 4 shows the introduction trend of major ME equipment. This figure is based on the field survey of the author. Electrical discharge machines began to be introduced in the 


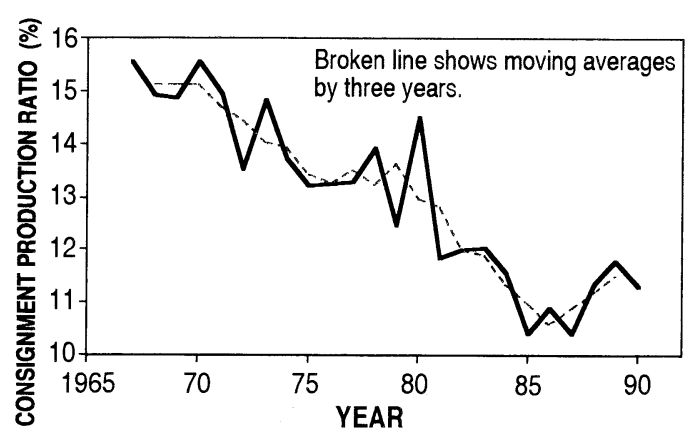

Figure 5. Consignment production ratio of the Japanese mold industry, 1967-1990. Consignment production ratio=Income by consignment/Mold output. Source: Based on Census of Manufactures.

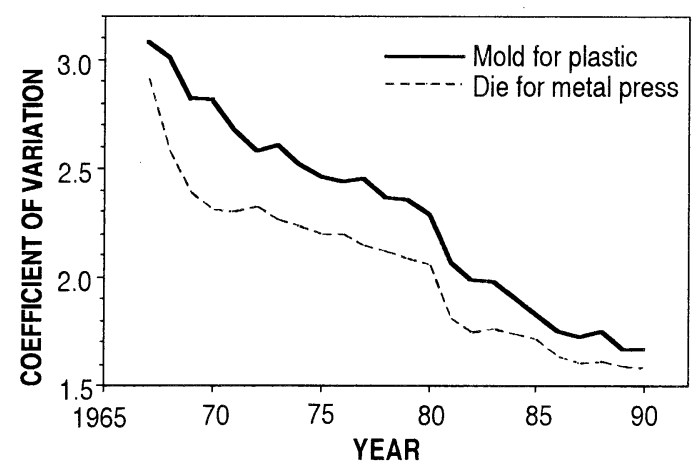

Figure 6. Coefficient of variation of factories number producing mold by prefectures in Japan, 1970-1990.

Source: Based on Census of Manufactures.

first half of the 1970s and were diffused rapidly in the beginning of the 1980s. Fundamental NC machine tools, such as NC milling machines, machining centers ${ }^{8}$ and $\mathrm{NC}$ electrical discharge machines, were diffused, accompanied by automatic programming devices approximately four years later than the spread of electrical discharge machines. Furthermore, the CAD/ CAM system was introduced rapidly into the late 1980 s through the early 1990s. ${ }^{9}$

Next Figure 5 shows trends of transition of the consignment production ratio of the mold manufacturing industry. This ratio is the index that shows the intensity of ties through the consignment processing between manufacturers. In this case it shows transition of intensity of mutual dependence between the mold manufacturers. A rapid decline in mutual depend-

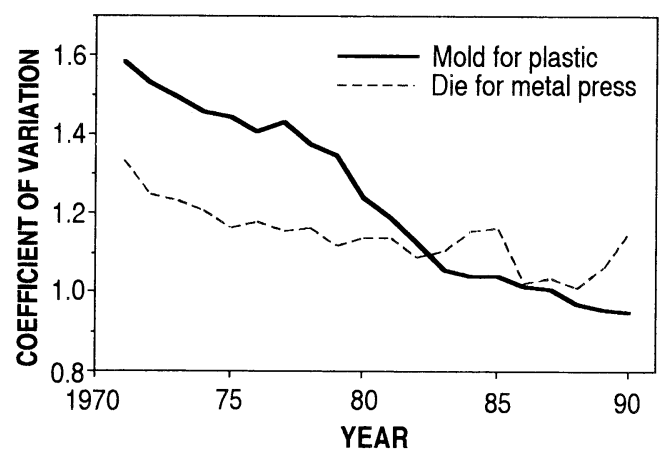

Figure 7. Coefficient of variation of moldoutput by prefectures in Japan, 19701990.

Source: Based on Census of Manufactures.

ence was noticed later in the 1980 s.

Figure 6 and Figure 7 show the trend of locational transfiguration. Figure 6 shows the coefficient of variance of a number of mold establishments in every prefecture. The index of the number of establishments implies the locational variation of mainly small establishments. With the coefficient of variance reducing all the way, there was an important turning point, namely a rapid dispersal at the beginning of the 1980s. On the other hand, Figure 7 shows the coefficient of variance of mold output reflecting the behavior in relatively large-scaled establishments. There is a continuous decline in this figure too. It is noticed that there was the rapid locational decentralization for five years around $1980 .{ }^{10}$

The most rapid variation in both indices that show technological or organizational transformation and locational change overlapped from the end of the 1970s to the first half of the 1980 s. It was just at the time when locational decentralization proceeded during the $\mathrm{ME}$ innovation.

\section{Development of Plastic-Mold Production in the Peripheral Area: The Case of the Southwestern Part of Ibaraki Prefecture}

\section{Overview of the study area}

The southwestern part of Ibaraki Prefecture (Southwestern Ibaraki) is located in this northeast peripheral area of Tokyo in the range of 40 


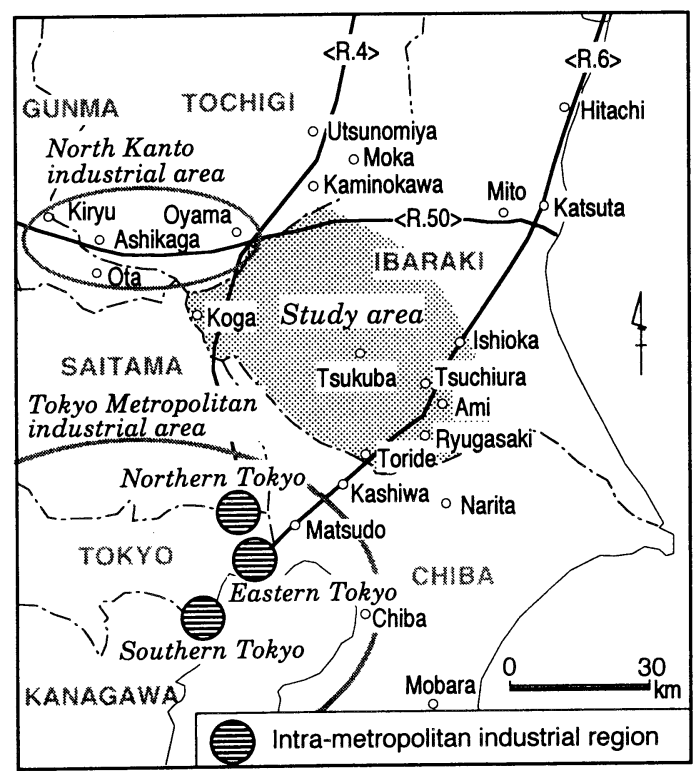

Figure 8. Location of the study area.

to 80 kilometers from the center of Tokyo. This region has long been left behind in the stream of industrialization, while industrial regions have grown in the cities of Hitachi and Katsuta in the north and Ota and Ashikaga in the west (Figure 8).

Since the 1960s, the development plan for industrial parks set by the Metropolitan Area Development Law has contributed to the establishment of inland industrial parks in the area. However, the companies which relocated to Southwestern Ibaraki belonged to material or daily consumable goods industries, which do not involve the development of related industries. For this reason, their locations did not bring forth any obvious ripple effect in the area (Ji 1988; Suyama et al. 1990; Oda et al. 1994). Although research industrial parks were developed in the Tsukuba Science City in the 1980s, regional production linkages again have been weak due to their focus on fundamental research laboratories of materials and pharmaceutics (Nakagawa et al. 1994.

There are only a small number of leading companies engaged in the fabrication or assembly sector in Southwestern Ibaraki in response to the advancements of material or daily consumable goods industries. Among these companies are included the Toride plant of Cannon
Inc., which started operation in 1961, and its Ami plant, which started operation in 1981. The reasons why the industries of durable consumable goods or capital goods, in other words, the complex of machine and metal industries, did not establish themselves in the area can be summarized in the following points.

First, there were no preceding industries which generally form the basis for the development of modern industries. For this reason, neither aspects of technology nor capital accumulation promoted the establishment of the small- and medium-sized machinery manufactures. This contrasts sharply to the north Kanto industrial area, in a narrow sense, centering on the cities of Ota and Ashikaga, which developed on the basis of the preceding military and textile industry.

Second, it can be pointed out that the supply of labor force was not extensive. The north Kanto industrial area enjoys a good supply of labor force from large areas of northeastern Japan. In contrast, Southwestern Ibaraki was not successful in attracting big companies to the area due to its disadvantages in the labor procurement, which are caused by its inconvenient traffic location.

The third reason can be attributed to its traffic location. The prefecture is located in the reverse sector to Southern Tokyo, which is the center for small- and medium-sized machinery industry. For this reason, it has been very rare until recent years for machine and metal companies in Southern Tokyo to move to this area.

Thus, Southwestern Ibaraki has been slow to industrialize due to its locational disadvantages. In recent years, however, the small- and medium-sized machinery manufacturers from Tokyo are beginning to form important landscape elements in the rural region. In this chapter, the analysis will focus on how plastic-mold manufacturers have moved to Southwestern Ibaraki by overcoming the locational disadvantages of the area along with the recent technological innovations.

\section{History of mold production}

Figure 9 shows the distribution of plasticmold manufacturers in Ibaraki Prefecture. The distribution is centered in the south part of the 


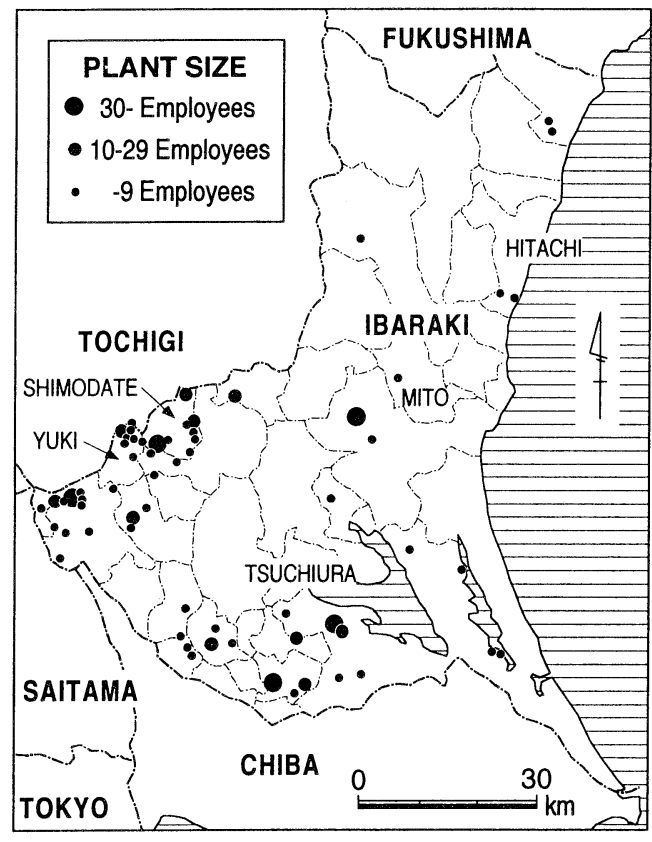

Figure 9. Plastic-mold factories in Ibaraki Prefecture, 1993.

Source: Based on The Establishment List of Ibaraki, The General List of all factories in Japan and Yellow Pages.

prefecture adjacent to National Route 6 as well as the west part adjacent to National Route 4 .

There is a difference between the south and west prefecture in the time of establishment of the plastic-mold manufacturers under the investigation. Because of the comparatively favorable conditions of external economies, the establishment was earlier in the west of the prefecture, which is adjacent to the core industrial towns in the north Kanto industrial area, such as the cities of Oyama and Ashikaga. On the other hand, establishment was late in the south of the prefecture, which is far from the existing industrial regions (Figure 10). This phenomenon can be explained as the dispersal process through the hierarchy of industrial areas.

The first plastic-mold manufacturer under investigation to advance to the area was a company which started operation in Koga City in 1949. Following this company are those which started operation in 1971-1973 in the west of the prefecture. Despite the fact that the west prefecture was comparatively favored with ex-

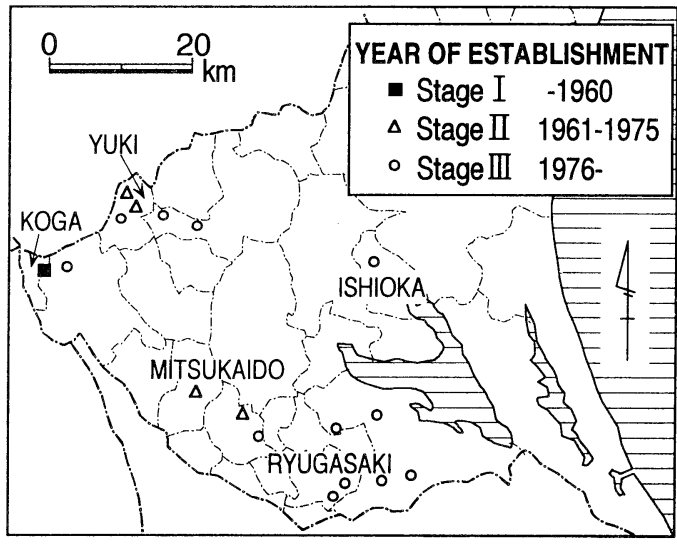

Figure 10. Year of establishment of sampled mold manufactures in Southwestern Ibaraki, 1994. Source: Based on field survey.

ternal economic conditions, it was undoubtedly the boundary of mold production until the first half of the 1970s. As described later, the production of mold calls for special steel material, tools and processing, which in many cases must come from Tokyo. The area was located in a boundary distance for an employee of mold manufacturer to go to Tokyo to procure the necessary materials and return on the same day. It was after the latter half of the 1970 s when the mold manufacturers began to advance to Southwestern Ibaraki in earnest, and it was not until the 1980s when most of the currently existing companies began to do so.

Figure 11 shows where sampled plastic-mold manufacturers learned the mold technologies or where their main plants are located. ${ }^{11}$ Three of these companies established their branch (satellite) plants in this area. Among them, two companies have their main plants in Eastern Tokyo, and one company has its main plant in Southern Tokyo. Other companies have established their plants in Southwestern Ibaraki either by independence or by relocation from other regions. It is worth noting that more than half of them have acquired the technologies from Southern Tokyo before advancing to this region. From the above, it can be said that Southern Tokyo has played a key role in spreading the plastic-mold technologies.

When asked for the reasons for having established a factory in Southwestern Ibaraki, six of 


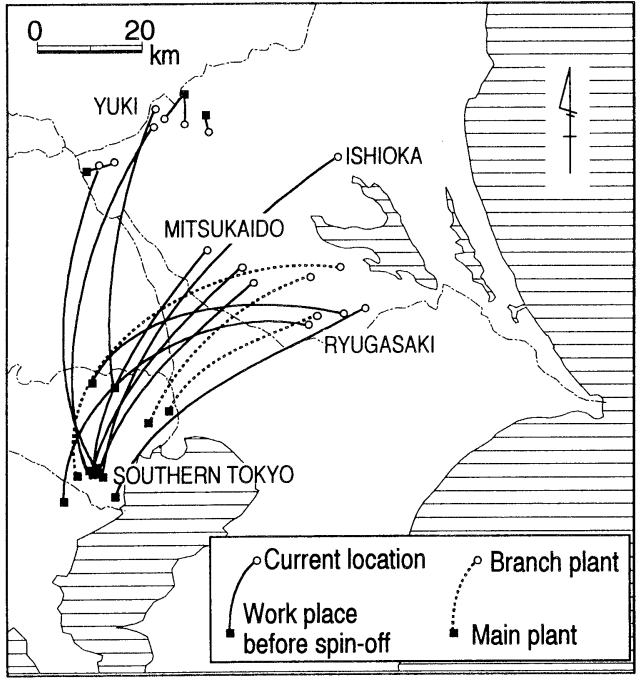

Figure 11. History of sampled plastic-mold manufactures in Southwestern Ibaraki, 1994.

Source: Based on fieled survey.

13 companies, which either have become independent or have relocated from other prefectures, answered that it is the home prefecture of the president. Five companies answered that it is close to their business acquaintances, and two answered that it is located relatively close to Tokyo. The home town orientation and geographical distance to business acquaintances are the major motives for the movement to the area.

Despite some differences in the situation immediately after establishment, the major customers of most companies are still located in Ibaraki Prefecture or the adjacent Tochigi Prefecture (Figure 12). In contrast to Southern Tokyo, where mold manufacturers possess a larger market (Oda 1997), the management of this region depends on the local market.

Figure 13 shows the current products. It demonstrates that approximately 30 percent of the companies produce molds for automotive parts, another 30 percent manufacture molds for exterior parts for light electronic appliances, and another 25 percent produce molds for interior parts for light electronic appliances. In this figure, the interior parts for light electronic appliances include automotive electrical parts, which account for about half of such produc-

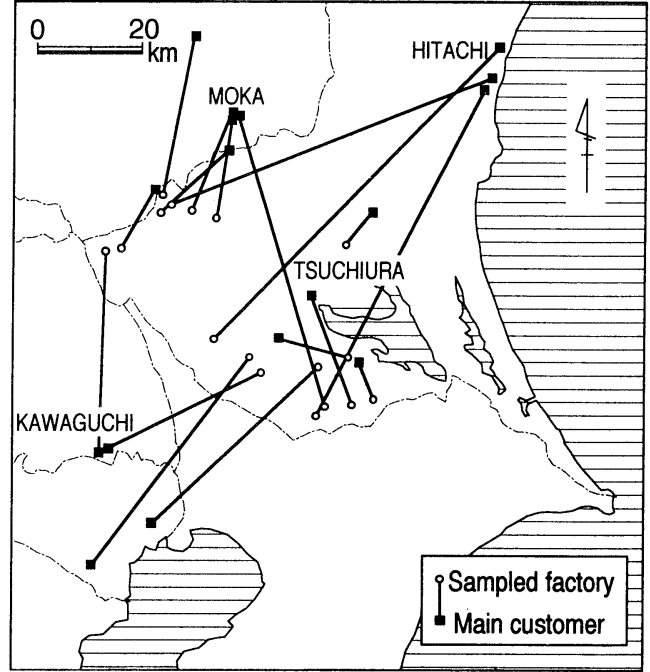

Figure 12. Forward linkages of sampled plastic-mold manufacturers in Southwestern Ibaraki, 1994.

Source: Based on field survey.

Ratio of mold makers that make each kind (\%)

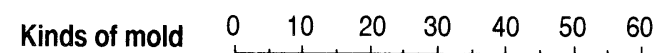

For car parts

For exterior parts of electrical machinery

For functional parts of electrical machinery

For machinery parts

For daily necessities

For the others

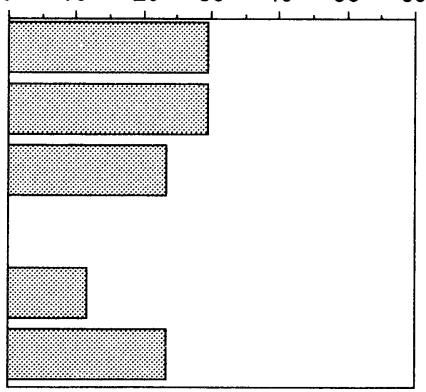

Figure 13. Kinds of mold made by sampled plastic-mold manufacturers in Southwestern Ibaraki, 1994.

$\mathrm{N}=17$. Redundant answers. Source: Based on field survey.

tion. The situation leads to the indication that the plastic-mold industry in Southwestern Ibaraki is specially dedicated to the production of molds for automotive parts. Some three years are necessary from the design stage to the mass production of automotive parts. During this period, many design or engineering changes are requested for prototype molds. In the natural course, it requires close face-to-face meetings to consider the nature of prototype products, which explains the necessity to be located close to the business acquaintances in order to manu- 
Table 1. Labor configuration of sampled plastic-mold manufacturers in Southwestern Ibaraki, 1994

\begin{tabular}{|c|c|c|c|c|c|c|}
\hline \multirow[b]{2}{*}{ Management types } & \multirow{2}{*}{$\begin{array}{c}\text { Average } \\
\text { number of } \\
\text { employees }\end{array}$} & \multirow[b]{2}{*}{ Average age } & \multicolumn{4}{|c|}{$\begin{array}{l}\text { number of sampled establishment by types } \\
\text { of the divition of labor }\end{array}$} \\
\hline & & & $\begin{array}{c}\text { part- } \\
\text { process- } \\
\text { specialization }\end{array}$ & $\begin{array}{l}\text { machine- } \\
\text { specialization }\end{array}$ & $\begin{array}{c}\text { non- } \\
\text { specialization }\end{array}$ & Total \\
\hline Capital-intensive & 18.9 & 29.7 & 0 & 3 & 1 & 4 \\
\hline Intermediate & 3.8 & 39.9 & 4 & 1 & 7 & 12 \\
\hline Skill-intensive & 2.0 & 60.0 & 0 & 0 & 1 & 1 \\
\hline
\end{tabular}

Source: Based on field survey.

facture prototype molds for automotive parts. ${ }^{12}$

\section{Introduction of capital equipment and labor configuration}

Management types As described above, the location of business acquaintances or home town orientation are, in many cases, direct motives for the migration of mold manufacturers to this region. However, there is a time gap for their migration which takes place after the establishment of component suppliers or molding companies following the location of final product makers. Furthermore, it is not always the case that a mold engineer who was born in the area and acquired technologies in Tokyo can immediately return to his home town when, during the course of his life cycle, it becomes necessary. This is because of the heavy dependence on the external economies of the intrametropolitan industrial regions, and so much so that, the dispersal of the industry to peripheral areas has been difficult unless the technical or regional assumptions are all met. In this respect, an in-depth study is required to treat a particular company as a unit for analysis. First, in this section, the study will focus on the introduction of production equipment as well as the utilization of labor force, which is closely related to the equipment. Second, in the next section, the division of labor among the companies will be considered from the aspects of space.

In the same way as Southern Tokyo (Oda 1997), the author will review the management by dividing it into three types: skill-intensive, capital-intensive and the intermediate types. The classification is based on possession of five typical ME devices such as NC milling machines, machining centers, electrical discharge machines, automatic programming apparatus and $\mathrm{CAD} / \mathrm{CAM}$ system. In the three strata, the capital-intensive type manufacturers have all devices and the skill-intensive type have either NC milling machines, electrical discharge machines, or neither of them. The samples that are not applicable to the above were categorize as the intermediate type.

Table 1 shows mean employee number, mean age and the division of labor configuration in each type. The division of labor configuration, which refers to the use of labor divisions in workshops, is classified into three categories. The first, part-process-specialization, is the technical division of labor according to partprocesses like the carving team and the finishing team. Second, machine-specialization causes further division of labor with every machine, such as milling machine team and electrical discharge machine team. Third, a case that does not correspond to both part-processspecialization and machine-specialization is classified as non-specialization.

Among the three types, there is only one company which belongs to the skill-intensive management category. This company is "S" Mold Mfg. Ltd. located in Koga City. The company is not making any investment for equipment in response to the recent technological innovations due to the fact that the president is at an his advanced age and there are no successors. However, this example is rather exceptional, and the management styles that characterize this region are either intermediate or capital-intensive types.

As for the intermediate type, the average number of employees does not reach four. While companies of similar type in Southern 


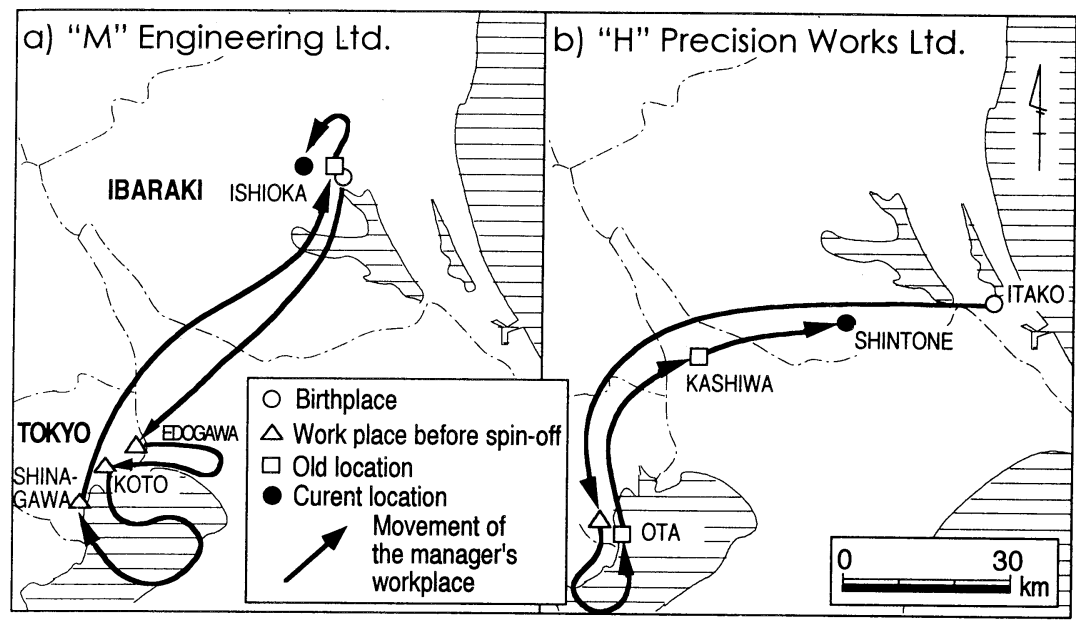

Figure 14. Examples of the history of medium-typed plastic-mold manufacturers, 1994. Source: Based on field survey.

Tokyo have an average of nine employees, most companies in this region consist of the president alone or he and his family. In addition, the roles of employees are not well separated in most cases.

On the other hand, the average number of employees for the capital-intensive type management is 19 , and some big companies employ as many as 40 employees. The average age is young, below 30 . Compared with the companies of similar type in Southern Tokyo whose average age is 37 , the capital-intensive type in this region can be referred to as large-scale management which utilizes the young workers.

Using examples, the intermediate and capitalintensive types will be reviewed in order below.

\section{Development of intermediate type management} Figure 14 demonstrates two examples for the relocation of companies which can be classified as intermediate type management. Among these companies, the president of "M" Engineering Ltd. is originally from Ishioka City. Upon moving up to Tokyo at the age of 18 , he was employed by a glass mold manufacturer in Edogawa Ward, Tokyo for two years, then by a plastic-mold manufacturer in Koto Ward for two years, and then by a plastic-molding company in Shinagawa Ward for five years. At the age of 28, in 1975, he became independent and established a business at the site of his parent's house located in downtown Ishioka City. He thought it was better policy than to rent a premium factory in Southern Tokyo because the savings could be spent for investment in production equipment. He introduced an electrical discharge machine at an early stage, and introduced various kinds of advanced equipment ever since. In 1980, the company was relocated to the current location in the peripheral part of the city in preparation for the introduction of an NC machine.

Next is an example of " $\mathrm{H}$ " Precision Works Ltd. located in Shintone Village. The president is originally from Itako Town, and was born in 1931. After working for a mold manufacturer in Kamiikedai, Ota Ward, Tokyo for ten years, he became independent in 1959 at the age of 28 and started operation in Higashikamata, Ota Ward. Five years after that in 1964, however, the factory was relocated to Kashiwa City, Chiba Prefecture. The relocation was made in consideration of the distance to both of its customers located in Itako Town and Tokyo. In 1976, the factory in Kashiwa City was relocated to the current location in Shintone Village because the plant has become too small for its operation. By the middle of the 1970s, the business with Tokyo had been reduced, and the facility was relocated to Shintone Village due to the consideration that both customers were located in Itako Town and Edosaki Town. Like the aforementioned "M" Engineering Ltd., the company introduced an electrical discharge 


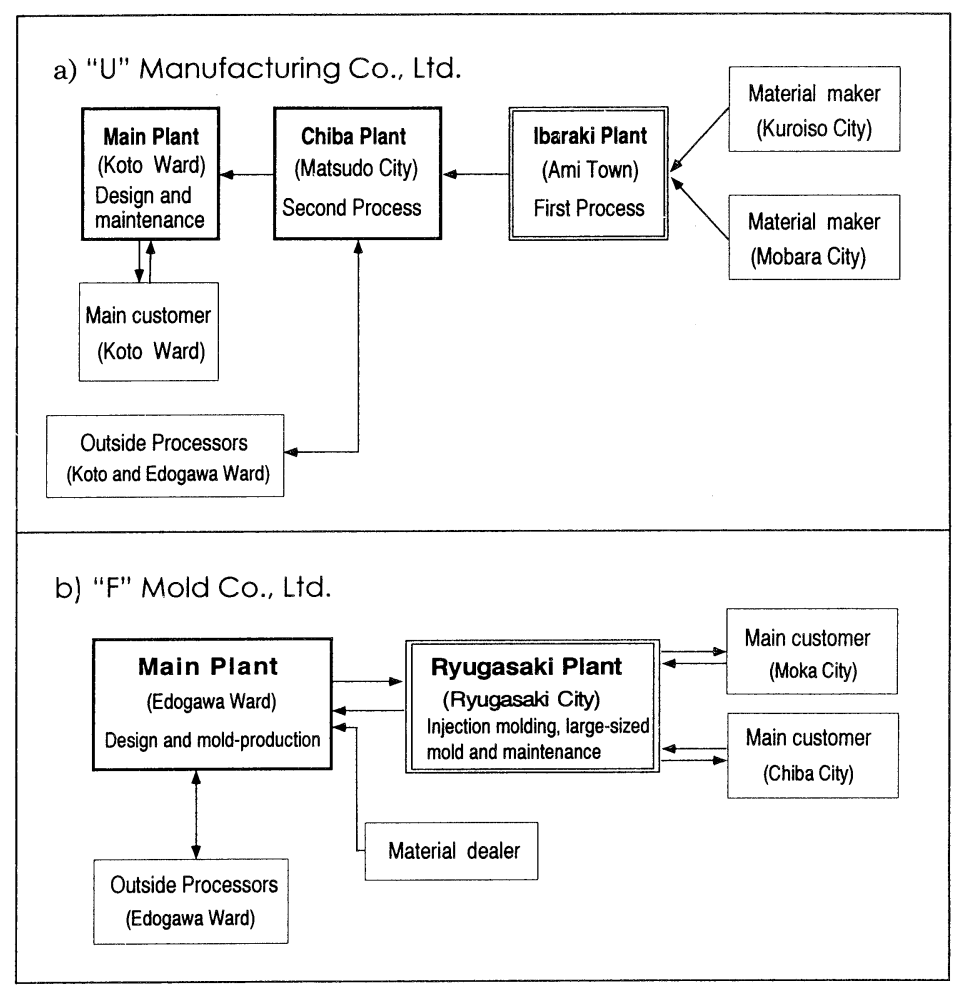

Figure 15. Input-output relations in multilocational plastic-mold manufactures, 1994. Source: Based on field survey.

machine upon relocation to Shintone Village.

Both these examples indicate that possession of an electrical discharge machine is mandatory for a small-sized mold manufacturer to be dispersed spatially. Generally, the processors for EDM can not be found in the peripheral areas, and therefore production with dependence on subcontractors as in the existing regions is difficult. Accordingly, it is considered that the decrease in the cost of electrical discharge machine has become a basic condition the dispersal described above.

Development of capital-intensive type management Among the 17 companies under investigation, four can be classified as capitalintensive management. Among them, three companies have their main plants in Tokyo and have allocated their branch plants to Southwestern Ibaraki. The other company is an independent operation but has become independent from a company in the prefecture instead of migration from Tokyo. Therefore, the author will analyze the cases with the three companies which have established their branch plants in the area. Figure 15 shows the examples of "U" Manufacturing Co., Ltd. and "F" Mold Co., Ltd. which have their branch plants in Ami Town and in Ryugasaki City respectively.

"U" Manufacturing Co., Ltd. has its origin in Eastern Tokyo and still has its main plant in Koto Ward. It is a plastic-mold manufacturer with a high market share in the production of molds for cosmetics containers and beverage bottles. The company was established in Honjo Ward, Tokyo City (then) in 1936, and after suspension of the business during the Second World War, it resumed business in the current location in Koto Ward in 1948. The Chiba plant was completed for business expansion in Matsudo City in 1963, and Ibaraki plant was completed in Ami Town in 1982.

The most important reason for establishing the Ibaraki plant was to introduce a large NC machine. In recent years, it has become general for the production of daily merchandise to use a 
mold called a "multiple cavity mold". The molds have a tendency to become larger and larger due to the fact that by increasing the number of products that can be produced per single injection, the production time and expenses can be saved. In conjunction with this tendency, it has become necessary to increase the size of production equipment. About 40 percent of 25 employees in Ibaraki plant have been transferred from either the main plant or the Chiba plant but the remaining 60 percent are hired locally. The average age is as low as 28. Along with the opening of Ibaraki plant, the following spatial separation between the plants has been planned: for Ibaraki plant to perform the making of mold material and to lathing; Chiba plant to perform engraving and heat treatment; and the main plant, which is close to the business acquaintances, to perform design and modification which requires face-to-face contact with them. Owing to the development of labor separation between plants that involves the introduction of $\mathrm{ME}$ machine, it has become possible to expand the business to peripheral areas by utilizing young labor force and decreasing the necessity to employ expert, multi-skilled workers.

Next, the author will take a look at " $F$ " Mold Co., Ltd., a mold manufacturer which supplies plastic-molds to the automotive component supplier which belongs to the Nissan Group. This company also originates in Eastern Tokyo. It was established in 1962 in the current location of its main plant in Edogawa Ward. The factory in Ryugasaki City has existed since 1967 but was originally engaged in the molding of plastic products, and not the production of molds. Because its major customers were located in Moka City and in Chiba City, the company chose the location between these two companies. It was not until 1991 that the mold shop was established in Ryugasaki plant. The introduction of large equipment was the reason for it. There is only a single employee among its 27 employees in Ryugasaki plant, who is responsible for the mold shop. Ryugasaki plant is responsible for the production of larger molds, which is difficult for the equipment at the main plant to handle. The main plant transmits the data by telephone line, and the NC machine

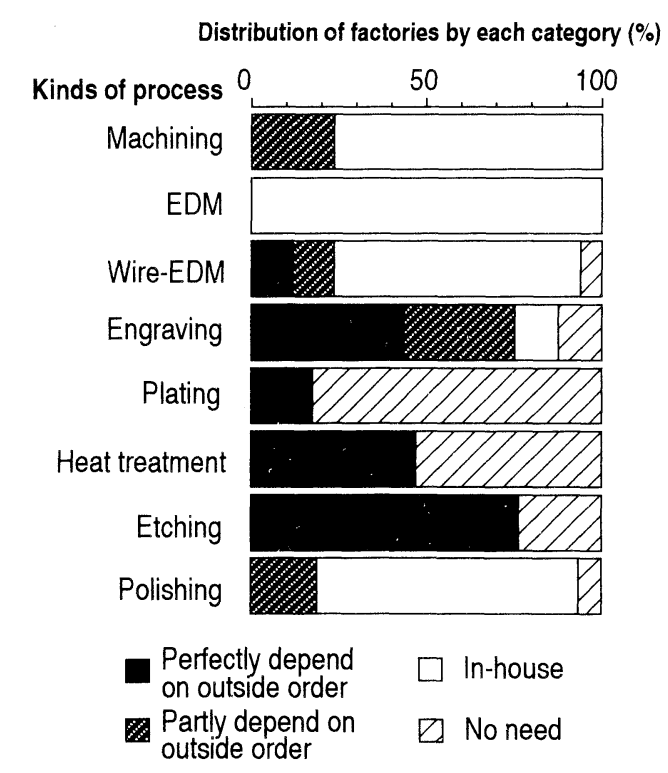

Figure 16. Dependance on outside orders of sampled plastic-mold manufacturers by kinds of processe in Southwestern Ibaraki, 1994. $\mathrm{N}=17$.

Source: Based on field survey.

operates based on the data.

In both examples, the introduction of large equipment is the driving factor to establish a mold factory in peripheral areas. It was the development of ME technologies which has enabled the geographical separation of some of the processes.

Thus far, the author has reviewed examples of intermediate and capital-intensive management types. Based on the review, three things can be pointed out. First, the precondition for advancement common to both types is not to use too many skilled workers. Second, the introduction of electrical discharge machine is the precondition for the intermediate type company. Third, in the case of capital-intensive management, the introduction of large $\mathrm{ME}$ equipment is the decisive factor for the allocation of a new plant to this region.

\section{Division of labor and linkage structure}

Figure 16 shows the subcontracting status for each process. It can be pointed out that the dependency on subcontractors is generally small in Southwestern Ibaraki. In particular, 


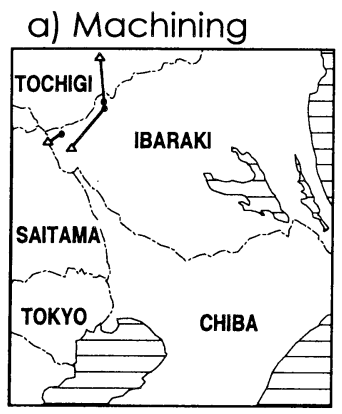

\section{b) Wire-EDM}

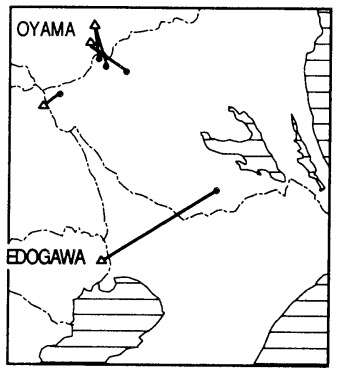

e) Heat treatment c) Engraving

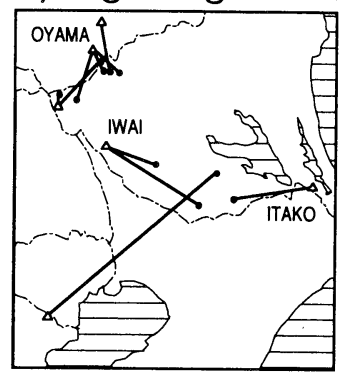

d) Plating
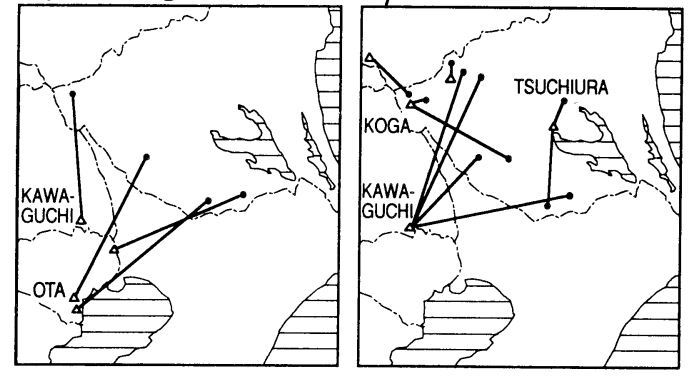

f) Etching

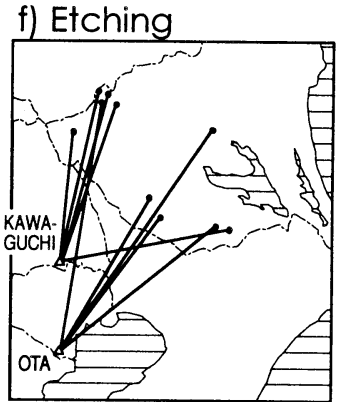

- Sampled plastic-mold manufacturer

$\triangle$ Mold-related processor

- Linkage

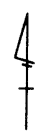

Figure 17. Linkages between sampled plastic-mold manufacturers and mold-related processors in Southwestern Ibaraki, 1994.

Source: Based on field survey.

machining and EDM are performed basically in-house, and in contrast to Southern Tokyo, the companies in this region do not require plating and heat treatment in many cases. The reasons for such a low level of dependency on subcontractors are considered to be, first of all, that the area depends on standardized steel, especially on pre-hardened steel. Only a single company among the 17 answered that they sometimes order steel of special specifications in lieu of the standard specifications. Second, they manufacture products in-house as much as possible because they do not have many subcontractors that they can depend upon. Particularly noteworthy is that all companies own electrical discharge machines and none of them uses subcontractors for EDM.

As is obvious from the above, the division of labor and the linkage structure between companies in Southwestern Ibaraki is significantly simplified, which is considered to be the precondition for management in the area which is not favored with external economic conditions. In other words, it can be pointed out that the standardization of metal material as well as the reduction or simplification of the division of labor and the input-output relations, driven by the price decrease of machine, such as electrical discharge machine, are the fundamental conditions for the dispersal of mold manufacturing industry to peripheral areas.

In mold production, however, it is indispensable to maintain relationships with other moldrelated processors. Although the roles of subcontractors are relatively small as compared with Southern Tokyo, there is some newlyarising dependency on subcontractors and the forming of a spatial relation to the mold-related processors in the other regions. Figure 17 shows the typical subcontractors by each process. There are orders for machining or wireEDM inside Southwestern Ibaraki or from the west prefecture to Tochigi Prefecture, but the linkages inside the south prefecture can not be recognized. The etching and plating depend on outside the prefecture and are ordered to com- 
panies in the Tokyo region. With the exception of Kawaguchi City, heat treatment depends on specialist companies inside the prefecture, which are located in the inland industrial parks developed in the 1960s. However, heat treatment is limited to the surface nitriding of parts, and does not include the complete hardening which is done in Southern Tokyo.

Figure 18 shows schematically the subcontracting linkages described above. Etching and plating indicate a high level of spatial linkages, and are dependent on external economies of the intra-metropolitan industrial regions. Engraving and heat treatment depend on companies in the prefecture and indicate an intermediate level of linkages. On the other hand, as far as the low level of linkages, such as lathing and wire-EDM, is concerned, it is only companies located in proximity to the core district of the north Kanto industrial area that can benefit from the use of subcontractors.

In the west of the prefecture where mold manufacturers are relatively densely distributed and adjacent to the industrial regions of Tochigi and Gunma Prefectures, it is often the case in recent years that steel traders and intermediate companies are involved in various subcontracts. Those companies visit manufacturers and consolidate the products on a regular basis.

On the other hand, the south of the prefecture is not relatively favored with the availability of material procurement and subcontracts. In the case of "M" Engineering Ltd. in Ishioka City, the company was using a steel distributor in Meguro Ward, Tokyo, for the delivery of steel material immediately after the establishment. Because a close relationship has existed with the distributor since the time when the president was working in Tokyo, they did the favor of delivering steel despite the long distance. An employee of the steel distributor took a whole day to make the round trip for the delivery. The company ordered tools to a distributor in Tokyo by sending cash by a registered mail and received them by mail package. For a subcontracted processing that has a high level of linkages, such as etching, the order was made after the delivery of mold to customer, and the subcontractor finished the final assembly inside
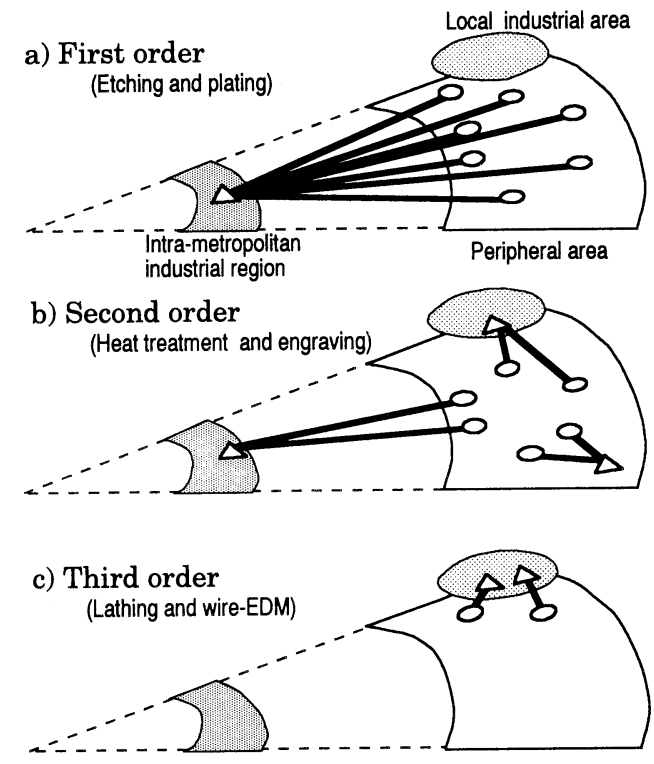

\section{OMold maker $\Delta$ Mold-related processor - Linkages}

Figure 18. Spatial hierarchy in linkages of plastic-mold production in the peripheral area.

the customer's plant. It was not until the 1980s when the delivery system for small-lot consignment began to be used, for which progress in the standardization of specifications was the precondition.

Although the above example applies to a mold manufacturer with a single plant location, the low dependency on subcontractors is the same with a company with multiple locations. In the case of a mold manufacturer with multiple locations, its branch plant in Southwestern Ibaraki is responsible for processes that do not require subcontracts. For example, in the case of the aforementioned " $U$ " Manufacturing Co. Ltd., all subcontracted processes, such as etching, plating and engraving, are ordered from its Chiba plant in Matsudo City. Furthermore, the heat treatment is performed in-house at Chiba plant. Again in this example, the companies which do business with its Ibaraki plant are limited to steel suppliers. The same applies to "F" Mold Co., Ltd. whose orders for subcontracted processing are all made from its main plant, and there are no processes at its Ryugasaki plant which require subcontract (Figure 
15).

\section{Conditions of peripheral locations}

In Southwestern Ibaraki, mold production has developed along with the progress of technological innovations, which have become important and fundamental condition for the geographical dispersal of production sites for major manufacturing industries. The west of the prefecture saw the emergence of mold manufacturers at a relatively early stage, owing to its favorable external economic conditions. But it was not until the 1980s when the emergence accelerated to wider areas, including the south, by migrations from Tokyo.

Taking a look at individual companies which have moved to Southwestern Ibaraki, their reasons for allocation to the current location include the acquisition of production site, home town of president, closeness to customers, and so forth. It must be pointed out, however, that their preferences for location as an assumption for dispersal have changed along with technological innovations.

First of such innovations are the development of special steel for mold, the standardization of specifications, and the spread of electrical discharge machine. Therefore, the necessary number of processes for mold has been reduced, which in turn has reduced the necessity to depend on associated subcontractors. As Figure 19 indicates, there are distinct differences between Southern Tokyo and Southwestern Ibaraki in their subcontracting status.

Secondly, the microelectronization of machine and equipment have enabled the spatial separation of production processes inside a company, which has further enabled the largescale management which utilizes unskilled young workers. In addition to these, it can be pointed out that the innovation in transportation technology, i.e. the development in the delivery system for small-lot consignment, has played an important role. The development in the delivery system for small-lot consignment has enabled the prompt delivery system of standardized steel material, and has further made some portions of subcontract possible, which otherwise must depend on intra-metropolitan industrial regions.

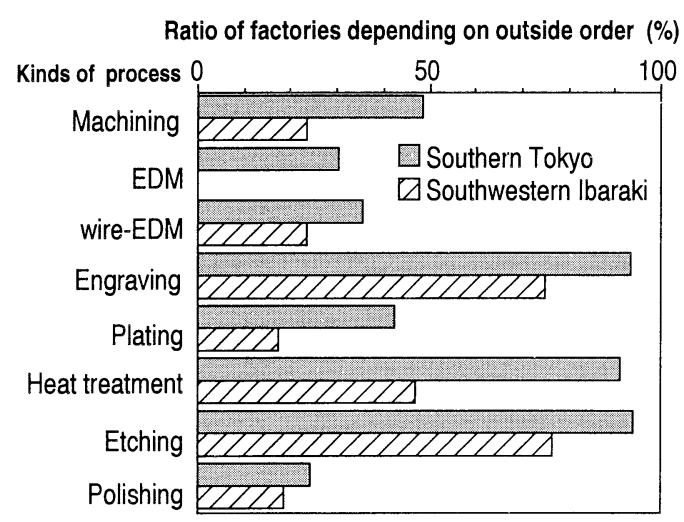

Figure 19. Dependance on outside order of the sampled plastic-mold makers by processes in Southern Tokyo (1993) and Southwestern Ibaraki (1994). $\mathrm{N}=51$.

Source: Based on field survey.

Although the author has seen thus far the progress in the dispersal of the mold manufacturing industry, and what has made it possible to run the business with relatively low labor and land costs, there are some disadvantageous locational conditions that need to be pointed out. First of all, it is difficult to manufacture a mold with high added value in this region. This is because the area does not allow a high-level heat treatment called "complete hardening" as well as engraving, which has to rely on particular skilled workers. Secondly, it is difficult to have flexibility in the adjustment of equipment investment and employment in relation to the fluctuation in production volume caused by the changes in economic environment. This is because this region is not favored with subcontractors which save the capital investment for production equipment and because this region does not possess a specialized labor market that can be recognized in Southern Tokyo.

\section{Conclusions}

This paper aimed to elucidate the locational dynamics of the machinery industry during the $\mathrm{ME}$ innovation in the context of production system dynamics, taking the Japanese plasticmold industry as an example.

Firstly, we considered the changing locatio- 
nal tendency of the industry. The development of Japanese mold technology has formed the basis of the mass production of durable customer goods with a dependence on skilled labor. When the Japanese industry as a whole experienced drastic decentralization in the 1960s and early 1970s, the mold industry maintained centralization in existing industrial regions with its oligopoly. However, during the recent technological innovation, the mold industry also experienced rapid locational dispersal into peripheral areas. The first innovation in the mold industry lies in the input field, such as special steels for mold and the standardization of parts. The second is the process innovation, namely the development of new machines, such as electrical discharge machines and each seed NC machine tools.

Secondly, we examined conditions of peripheral location. In the study area, mold manufacturers try to depend on skilled labor and inputoutput relations with mold-related processors as little as possible. This kind of production style is in contrast with the metropolitan style of mold production, which depends on external economies. This contrast gives evidence for the tendency to change location with innovation. However, though locational dispersal was brought about, it is difficult to produce high added value products in a peripheral area. In contrast, as Oda (1997) points out, intrametropolitan mold production has had to specialize in high added value production, utilizing abundant mold-related processors, because of high central wages and rents.

In conclusion, this study which analyzed the plastic-mold industry from the viewpoint of the division of labor and external economies, shed light on the locational dynamics of the industry during the innovation in which locational dispersal occurred and the regional differentiation of production progressed. The facts do not agree with the "re-regionalization" hypothesis in the neo-Marshallian flexible specialization approach. The approach might leave out the moment of locational dispersal attended by the ME innovation. Alternatively, it could be argued that the ME innovation raised the spatially wider networks of the small- and mediumsized manufacturers around existing agglom- eration structure.

The process can correspond not only with the mold industry but also with other industries. There may be a similar tendency in other industries which experience the substitution of skilled labor by capital equipment and the simplification or standardization of input-output relations with innovations. This approach can especially be applied to small- and medium sized machinery industries that have been formed in intra-metropolitan industrial regions.

\section{Acknowledgements}

This paper is based on a dissertation submitted to the University of Tsukuba for a Ph.D. (in Science) in 1996. The author expresses his appreciation to his academic advisor, Prof. Dr. Nobuo Takahashi and other scholars of the Institute of Geoscience, the University of Tsukuba, for their kind and useful advice.

In the field survey, the author received generous collaboration from the staffs of the Japan Association of Mold Manufacturing Industry and the Keihin Plastic-Mold Industry Cooperation, and the mold and mold-material makers' staffs. I wish to give special thanks to all of them. I would also like to express my thanks to Prof. Dr. Atsuhiko Takeuchi and other staffs of the Nippon Institute of Technology, and $\mathrm{Mr}$. Satoshi Kitamura and other members of the Research Group of the Keihin Industry for their useful comments and encouragement.

The abstract of this article was presented at the 1995 spring conference of the Association of Japanese Geographers.

(Received Mar. 26, 1996)

(Accepted Mar. 29, 1997)

\section{Notes}

1. According to The Machinery Statistics edited by MITI.

2. About mold production, Oda (1991) pointed out that understanding of the locational dynamics of the supporting industry such as the mold industry gives a base for understanding the production systems of large-sized final assembly industries. Oda (1993) considered the development of the mold production in the Tsubame-Sanjyo area as a provincial industrial center.

3. The beginnings of controversy about the incubator hypothesis was begin by Hoover and Vernon (1959). Their book was based on a joint research project on the New York metropolitan area by the New York Regional Plan Association consisting of Harvard University members 
in the late 1950s. Because the main author of this book was Vernon who had shown the product cycle theory, the hypothesis has often been thought of as supplementary to the theory.

4. According to Seki and Kato (1990:115), 45 percent of machine shops in Ota Ward, Southern Tokyo, uses mainly machine tools.

5. Injection is a kind of method that forms thermosetting resin and thermoplastic resin.

6. Member of the Kanto Association of Mold Manufacturers went to Germany, France, UK, Italy, Switzerland and Sweden to inspect mold technologies. They acquired technology of heat treatment in Sweden.

7. A mold base means a set of mold plate for injection-plastic-mold.

8. A machining center is a multi-task machine tool that has APC (Automatic Pallet Changer) and ATC (Automatic Tools Changer). It can continually perform a series of machining, such as boring, drilling and milling, with automatically changing tools by control program.

9. Instead of indices in Figure 4, ratios of introduction of each device in 1993 are as follows: electrical discharge machines, 82 percent; NC electrical discharge machines, 82 percent; NC milling machines, 80 percent; machining centers, 42 percent; automatic programming devices, 76 percent; and CAD/CAM systems, 36 percent.

10. Regarding coefficient of variation as an index of geographical distribution, see Nishioka (1973: 261-284). There are some concealment data in Census of Manufactures that the author uses as a data source. Then the coefficient is based on 25 prefectures of mainly central Japan.

11. Figure 11 limits the presentation to two points: a workplace before their spin-off and a current location. If the manufacturers have experienced more than one workplace before their spin-off, the figure presents the most meaningful workplace for them.

12. On the other hand, prototype molds do not need durability, i.e. heat treatment and plating.

\section{References}

Akaike, M. 1990. Change of the industrial location in Tokyo metropolis caused by technological innovations. Studies in Regional Science 21(1): 17-43. (JE)

Alderman, N. and Davies, S. 1990. Modeling regional patterns of innovation diffusion in the UK metalworking industries. Regional Studies 24: 513-528.

Berry, J. L. 1972. Hierarchical diffusion: the basis of development filtering and spread in a system of growth centres. In Growth centres in regional eco- nomic development. ed. N. M. Hansen, 108-138. New York: The Free Press.

Cameron, G. C. and Evans, A. W. 1973. The British conurbation centers. Regional Studies 7: 47-55.

Evans, A. W. 1985. Urban economics: an introduction. London: Basil Blackwell.

Gibbs, D. C. and Edwards, A. 1985. The diffusion of new production innovations in British industry. In The regional economic impact of technological change. ed. A. T. Thwaites, and R. P. Oakey, 132163. London: Frances Printer.

Harris, R. I. D. 1988. Technological change and regional development in the UK: Evidence from the SPRU database on innovations. Regional Studies 22: 361-374.

Hoover, E. M. 1937. Location theory and the shoe and leather industries. Cambridge: Harvard University Press.

Hoover, E. and Vernon, R. 1959. Anatomy of a metropolis. Cambridge: Harvard University Press.

Hori, K. 1985. The organization of small- and mediumsized machinery industries with microelectronics innovation: A case study of the Keihin area. Syoko Shido No. 398: 1-14. (J)

Isard, W. 1948. Some locational factors in the iron and steel industry since the early nineteenth century. Journal of Political Economy 56: 203-217.

Ji, Z. 1988. Productive activities in industrial park and changes in the surrounding rural area. Human Geography 40: 387-401. (JE)

Kleine, J. 1985. Location firm size and innovativeness. In Technology: A key factor for regional development. ed. D. Maillet, 147-173. London: Georgi.

Leone, R. A. and Struyk, R. 1976. The incubator hypothesis: Evidence from five SMSAs. Urban Studies 13: 325-331.

Lichtenberg, R. M. 1960. One-tenth of a Nation: National forces in the economic growth of the New York region. Cambridge: Harvard University Press.

Martin, J. E. 1966. Greater London: An industrial geography. London: G. Bell and Sons.

Nakagawa, T., Suyama, S., Oda, H., Ji, Z., and Hirota, I. 1994. Agglomeration of private research institutions in the Tsukuba Science City. Science Reports of the Institute of Geoscience, University of Tsukuba, Section A 15: 107-122.

Nishioka, H. 1973. Ritti to chiiki keizai (Location and regional economies) 3rd edition. Tokyo: Miyai. (J)

Norton, R. D. and Rees, J. 1979. The product cycle and the spatial decentralization of American manufacturing. Regional Studies 13: 141-151.

Oakey, R. P., Thwaites, A. T., and Nash, P. A. 1980. The regional distribution of innovative manufacturing establishments in Britain. Regional Studies 14: 235-253.

Oda, H. 1991. Industrial development and production system in the Kitakami area. Area Research Papers No. 13: 101-112. (J)

Oda, H. 1993. Developing of the mold industry in the 
Tsubame-Sanjyo area. Area Research Papers No. 15: 113-122. (J)

Oda, H. 1997. The transformation of the metropolitan machinery production system during the microelectronics innovation: A case study of the mold manufacturing industry in the Keihin area. Geographical Review of Japan 70A: forthcoming. (JE)

Oda, H., Kashima, H., Shinohara, S., and Hamasato, M. 1994. Industrial development in Ishioka, Ibaraki Prefecture. Area Research Papers No. 16: 49-70. (J)

O'Farrell, P. N. and Oakey, R. P. 1992. Regional variations in the adoption of computer-numericallycontrolled machine tools by small engineering firms: A multivariate analysis. Environment and Planning A 24: 887-902.

Piore, M. and Sabel, C. 1984. The second industrial divide: Possibilities for prosperity. New York: Basic Books.

Rees, J. 1979. Technological change and regional shifts in American manufacturing. Professional Geographer 31: 45-54.

Rees, J., Briggs, R., and Oakey, R. 1984. The adoption of new technology in the American machinery industry. Regional Studies 18: 489-504.

Sabel, C. 1989. Flexible specialization and the reemergence of regional economies. In Reversing industrial decline ?: Industrial structure and policy in Britain and her competitors. ed. P. Hirst, and J. Zeitlin, 17-70, Oxford: Berg Publisher.

Scott, A. J. 1988a. New industrial spaces: Flexible production organization and regional development in North America and Western Europe. London: Pion.

Scott, A. J. 1988b. Metropolis: From the division of labor to urban form. Berkeley: University of California Press.

Seki, M. 1994. Full set gata sangyo kozo wo koete (Beyond the full set- typed industrial structure). Tokyo: Cyuo-Koron. (J)

Seki, M. and Kato, H. 1990. Gendai nihon no cyusho kikai kogyo (The small- and medium-sized machinery industries in contemporary Japan). Tokyo: Shinhyoron. $(\mathrm{J})$

Suyama, S., Shinohara, S., and Mitsuhashi, H. 1990. Bases of the large plants in the Western Ibaraki.
Area Research Papers No. 12: 237-261. (J)

Steed, G. P. F. 1970. Changing linkages and internal multiplier of an industrial complex. Canadian Geographer 14: 229-242.

Steed, G. P. F. 1971. Internal organization, firm integration, and locational change: The Northern Ireland linen complex, 1954-1964. Economic Geography 47: 371-383.

Takeuchi, A. 1972. The bottom structure of the machinery industry in Japan, Keihin area. Human Geography 24: 404-422. (JE)

Takeuchi, A. 1973. Nihon no kikai kogyo (The Japanese machinery industries). Tokyo: Taimeido.

Takeuchi, A. 1978. Kougyo chiiki kozo ron (Regional structure of industries). Tokyo: Taimeido.

Takeuchi, A. 1983. Gijyutsu syudan to sangyo chiiki shakai (Engineer groups and industrial community). Tokyo: Taimeido.

Thompson, W. R. 1968. Internal and external factors in the development of urban economies. In Issues in urban economics. ed. H. S. Perloff, and L., Jr. Wingo, 43-62, Baltimore: Johns Hopkins Press.

Thompson, W. R. 1969. The economic base of urban problems. In Contemporary economic issues. ed. $\mathrm{N}$. W. Chamberlain, 1-49. Homewood: Richard D. Irwin.

Thwaites, A. T. 1978. Technological change, mobile plants and regional development. Regional Studies 12: 445-461.

Thwaites, A. T. 1982. Some evidence of regional variations in the introduction and diffusion of industrial products and processes within British manufacturing industry. Regional Studies 16: 371-381.

Tokyo Metropolitan Government 1964. Plastic kanagata seizogyo no jittai bunseki (The condition of plastic-mold industry). Tokyo: Tokyo Metropoli$\tan$ Government. (J)

Ukai, S. 1994. Gendai nihon no seizogyo (Contemporary manufacturing industry in Japan). Tokyo: Shinhyoron. (J)

Watanabe, Y. 1990. Social division of labor of the Japanese machinery industry: Part 2. Journal of Mita Association 82: 819-841. (J) 